\title{
CRISE DO FORDISMO, NEOLIBERALISMO E EDUCAÇÃO BRASILEIRA
}

\author{
Cristiano Lima Ferraz
}

Resumo: Na década de 1930 o Capitalismo encontrava-se em crise estrutural. Tal crise é debelada através de reformas estruturais no sistema e, durante anos de 1950-60 o sistema equilibra-se. No entanto, no início da década de 1970 inicia-se uma nova crise, e esta se perpetua até os dias atuais. Diante desse processo, uma das estratégias apontadas pela burguesia para se reverter a crise, é a ampliação subordinada da escolaridade dos trabalhadores.

Palavras-chave: 1. Fordismo, 2. Crise Capitalista, 3. Neoliberalismo, 4. Educação Brasileira.

Este artigo é fruto de algumas reflexões acerca das redefinições que se operam no encaminhamento das políticas educacionais no Brasil contemporâneo. Tais reflexões nos remeteram a uma análise de cunho histórico, evidenciando-se em seu decorrer, as bases em que se sustentam as referidas redefinições políticas no campo educacional. Diante disso, pretende-se aqui, tratar inicialmente sobre a gênese e decadência do Modelo de Desenvolvimento Fordista e a natureza da ofensiva neoliberal enquanto alternativa do capital para recompor suas bases de acumulação diante do processo de crise. Feito isso, procuraremos evidenciar algumas transformações no encaminhamento das políticas sociais, especialmente da educação, na sociedade brasileira tomando como referência o período que se segue de 1985 até nossos dias.

No decorrer dos anos 30 , os governos do Ocidente buscavam soluções para a crise do capitalismo que eclodira em 1929. Tal crise contribuiu para o fortalecimento de movimentos

"Cristiano Lima Ferraz é aluno do VIII semestre do curso de História da Universidade Estadual do Sudoeste da Bahia - UESB e Bolsista de Iniciação Científica do CNPQ.

Hist. Ensino, Londrina, v. 5, p. 87-102, out. 1999 
radicais como o fascismo na Itália e nazismo na Alemanha, como também cooperou para robustecer a posição soviética na geopolítica mundial no pós-guerra, pois, como a Rússia não se mostrava abalada pela a Grande Depressão, mais do que nunca se oferecia como alternativa viável a um capitalismo mundial abalado, se revelando uma ameaça real ao sistema de "livre empresa" (HOBSBAWM, 1995: p. 366). As economias capitalistas arruinadas (algumas também, além de arruinadas, encontravamse em situação de atraso) possuíam em suas entranhas desemprego em massa, insatisfação social e queda nos níveis de renda a índices funestos. Tudo levava a crer que o germe da destruição do sistema se não estava maduro, encontrava-se próximo disso (HOBSBAWM, 1995: p. 90).

Para não naufragar num oceano de adversidades econômicas e sociais, recorrentes ao período pós 1929, onde segundo Hobsbawm:

No pior período da Depressão (1932 - 3), 22\% a $23 \%$ da força de trabalho britânica e belga $24 \%$ da sueca, 27\% da americana, 29\% da austríaca, 31\% da norueguesa, $32 \%$ da dinamarquesa e nada menos que $44 \%$ da alemã não tinha emprego. Eo que é igualmente relevante, mesmo a recuperação após - 1933 não reduziu o desemprego médio na década de 30 abaixo de $16 \%$ a $17 \%$ na Grã-Bretanha e média ou $20 \%$ no resto da Escandinávia (HOBSBAWM, 1995: p. 97).

E sobretudo tentar conter a inclinação de esquerda que se desenhava no Ocidente no decorrer da II Guerra Mundial, onde o comunismo ganhou terreno na Europa com os movimentos de resistência (HOBSBAWM, 1995: p. 150), e ao mesmo tempo - a partir do fim da guerra - diante do fato de que era necessário a estabilização das economias do pós-guerra e modernizá-los para torná-los viáveis - sob pena de perder influência política e econômica para o bloco soviético - a cúpula do capitalismo mundial centrada em Washington, tinha claro para si que o sistema precisava de reformas. 
O liberalismo econômico do período entre guerras não era a alternativa, argumento reforçado pelos anos da Grande Depressão. A situação exigia um Estado mais presente planejando a economia - o que poderia evitar em tese as crises de superprodução - além de que a questão da reestruturação das economias arruinadas pela guerra e a retração dos níveis de desemprego demandavam esse tipo de ação governamental.

Após a II Guerra Mundial, a perspectiva de um Estado social-Democrata no ocidente correspondia a esses objetivos, o que contrariava a ortodoxia econômica. O Keynesyanismo ${ }^{1}$ se revelava uma tendência, quando não uma alternativa concreta. Os anos de crescimento econômico que se seguiram ao pósguerra denunciavam essa nova reestruturação do capitalismo. A economia mista - ou seja, com adaptações soviéticas no que se refere ao planejamento econômico e governo forte dentro do modelo capitalista - aliada ao Regime de Acumulação Fordista alcançava sucessos e estabilizou o sistema a despeito das críticas da ortodoxia econômica.

No decorrer do anos 50 - 60 o avanço tecnológico e o investimento em pesquisa e desenvolvimento alcançaram níveis nunca imaginados em outros tempos. A consolidação do sistema de produção fordista (LARANJEIRA in CATANI, 1994: p. 89-93) em escala mundial trazia em seu bojo, de forma germinal, os elementos de uma nova revolução científico-industrial como a microeletrônica, o uso generalizado de produtos gerados pela química fina, bem como uma explosão da produção e consumo de bens eletroeletrônicos e de automóveis. A explosão do consumo denunciava a elevação dos níveis de renda da classe trabalhadora nos países de capitalismo central. O capitalismo parecia ter reencontrado o caminho. Washington determinava 0 modelo a ser seguido se utilizando de instrumentos como o Fundo Monetário Internacional-FMl e o Banco Mundial, organismos financeiros internacionais criados no pós-guerra e diretamente

\footnotetext{
' O termo se origina do nome do economista inglês John Maynard Kaynes (1883 - 1946) que preconizava uma política sócio-econômica onde alguns anseios da classe trabalhadora fossem contemplados (por exemplo: seguridade social), assegurando também um certo padrão de consumo como forma de se garantir equilíbrio econômico e social. Cf.: HOBSBAWM op. cit., p. 100
} 
subordinados às políticas exteriores norte americanas que direcionavam suas ações e "tentáculos" aos países que após 1945, se alinharam com a hegemonia dos EUA (SOARES in DE TOMASI, 1996: p. 16). Quando as vias "legais" se mostravam ineficientes para alcançarem os objetivos políticos e econômicos norteados por Washington junto aos países de capitalismo periférico, o expediente de golpes militares fomentados pela CIA se tornavam rotina, em especial na América Latina.

Estabelece-se no processo, uma rede de relações econômicas internacionais que integraram os sistemas de forma mais ampla, cada vez mais transnacional, destacando-se nesse período (décadas de 1950-60) o papel das empresas transnacionais (multinacionais) numa nova divisão do trabalho. Fatores como mão-de-obra barata, custos de operações e de matérias primas determinavam a localização dessas empresas no globo, sendo que a partir da década de 1960 essas corporações internacionais "sem pátria" passaram a ver as fronteiras nacionais como um elemento complicador para suas atividades.

A existência de empresas desse tipo não era novidade. $O$ aspecto novo era a sua independência cada vez maior dos mecanismos de controle estatal, como também a mobilidade que seu capital atingia (HOBSBAWM, 1995: p. 272). Nesse momento - já meados da década de 1970 - começava a se esboçar traços de uma crise estrutural, pois o regime de acumulação TayloristaFordista ${ }^{2}$ começava a dar mostras de estagnação no que se refere à manutenção das taxas de lucro do período anterior à meados da década de 1960 e início da década de 1970 (SOUZA, 1998: p. 1). Paralelamente a esse fenômeno, começava-se a ganhar corpo o pressuposto neoliberal de Estado Mínimo - no que se trata do encaminhamento das garantias sociais para a classe trabalhadora - nos países capitalistas centrais.

No setor produtivo, a tecnologia eliminava cada vez mais

2 Taylorismo: racionalização do processo de trabalho introduzida nos EUA no início desse século por $\mathrm{F}$. W. Taylor através da cronometragem dos movimentos do trabalhador. Fordismo: inovação tecnológica na organização do trabalho fabril introduzida por Henry Ford no início do Século, na região de Detroit, caracterizada principalmente pela utilização da linha montagem e de maquinas-ferramentas para aumentar a produtividade do trabalho. 
os postos de trabalho, embora isso não fosse sentido devido ao grande crescimento econômico do período compreendido entre os anos de 1950 a 1970, período esse denominado por Hobsbawm como a "Era de ouro" do capitalismo mundial no século XX (HOBSBAWM, 1995: p. 253).

No entanto, a partir de 1973 inicia-se um novo momento de crise para o sistema capitalista mundial. No decorrer dos anos 70 , problemas que não eram percebidos de forma contundente como o desemprego gerado pela automação na indústria mostram a sua face. A esse fator soma-se a recessão conjugada à inflação acentuando o aspecto sombrio dessa nova crise.

É importante frisar que, com o avanço tecnológico das comunicações e dos transportes, a economia mundial, por volta dos anos 60 , se tornava cada vez mais integrada, dinâmica e transnacional. Outro elemento importante a ser considerado é o fato de que o capital financeiro formado nos anos de "boom" econômico se tornava cada vez mais independente dos mecanismos de controle dos Estados Nacionais. Nesse contexto as fronteiras nacionais e os limites impostos pelo Estado socialdemocrata com sua presença forte nas questões do mercado passam a ser vistos como obstáculo ao grande capital no processo de crise. Observa-se também nesse momento uma nova orientação na divisão internacional do trabalho, ou seja, os grandes conglomerados econômicos buscando aumentar os lucros no setor industrial, descentralizam a produção de países onde as conquistas da classe operária eram significativas através de altos salários e um forte sistema previdenciário mantido pelo Estado - o que onerava os impostos - para nações do terceiro mundo, pois nesses países a mão-de-obra custava menos e suas fronteiras e economias se revelavam menos protegidas contra 0 volátil capital financeiro internacional, como também, a organização do movimento operário encontrava-se mais enfraquecida.

Esses elementos contribuíram para a crise das concepções do Estado de economia mista (com elementos do socialismo, com o planejamento econômico pelo Estado), cujo modelo keynesiano era criticado pelos economistas ortodoxos 
mesmo quando a social democracia apresentava resultados positivos (HOBSBAWM, 1995: p. 176; SOUZA, 1998: p. 1).

Com a crise do regime de acumulação, as vozes de Fridrich Von Hayek (prêmio Nobel de economia em 1974) e Milton Friedman (prêmio Nobel de economia em 1976), teóricos do ultraliberalismo (HOBSBAWM, 1995: p. 398), solapam a base do kenesianismo com mais consistência. Diante da crise, as teorias neoliberais de desmonte do modelo kenesiano-fordista apontam para um novo modo de regulação no seio da sociedade política, onde o Estado estaria reduzido ao seu papel básico de reproduzir a ordem capitalista, diminuindo sua ação na área social, deixando que o mercado se auto-regule submetendo tudo à sua lógica e, de certa forma preservando em seus interesses. Observa-se a partir desse processo, uma redefinição das políticas estatais no decorrer dos anos 70 , em que o Estado neoliberal é apontado como instrumento político necessário ao processo de reestruturação capitalista.

A intensificação das políticas neoliberais nos países de capitalismo central se fazem sentir mais concretamente a partir dos governos de Margaret Thacher na Inglaterra, em 1979, e Ronald Reagan, EUA, em 1980 (LESBAUPIN \& ABREU, 1997: p. 10).

No Brasil, a partir de 1985 evidenciam-se as articulações políticas por parte dos setores hegemônicos e, sobretudo, das frações de classe mais "progressistas" - considerando-se o processo de ideologização que tenta propagar a essência do neoliberalismo como "novidade" e como uma concepção avançada - das forças conservadoras no sentido de dar rumos à política, economia e à regulação da sociedade, seguindo a orientação do que já acontecia nos países de capitalismo avançado ${ }^{3}$.

No decorrer do processo político, após o governo Sarney, elege-se em 1989 Fernando Collor de Melo apoiado pelo

\footnotetext{
${ }^{3}$ Compreendemos que no seio do bloco político das forças conservadoras, sobre tudo num momento de mudanças de paradigmas e Reestruturação Produtiva, divergem-se na estratégia política de condução do processo: os setores ligados às formas tradicionais de perpetuação da ordem dominante, e os setores progressistas dispostos a implementar modificações substanciais no sistema afim de se consolidar tal ordem e seu "status" de classe dominante face ao processo de reestruturação produtiva e política.
} 
empresariado, com o discurso de promover reformas para incluir o Brasil na "modernidade". Por questões que não cabem na nossa proposta de análise, o governo Collor não prossegue devido ao "Impeachemamt". O vice-Presidente Itamar Franco assume e retoma o projeto "modernizante". Contudo, segundo Lúcia Neves, no que se refere às redefinições das políticas educacionais, nos dois períodos de governo anteriores ainda existia uma atitude oscilante quanto às propostas estatais para a educação:

As ações educacionais do bloco no poder se dividiam entre ações destinadas ao resgate da dívida social e ações voltadas para o aumento da competitividade da produtividade da indústria nacional em face dos novos requisitos científicos e tecnológicos (NEVES, 1996: p. 77).

O que havia naquele momento, nos bastidores do poder, era uma luta por hegemonia entre frações de classe do bloco político dominante, polarizados entre os setores ligados ao PFL e os ligados ao PSDB (NEVES, 1996: p. 93-94). Com a estabilização econômica durante o plano real, a fração de classe ligada ao PSDB - ideologizada como progressista - hegemoniza, e o projeto dos grupos ligados ao PFL se vê obrigado a conformarse e alinhar-se com o projeto hegemônico. No fim do mandato de Itamar Franco já se percebe no âmbito econômico mudanças reais como a estabilização monetária, elemento que Fernando Henrique Cardoso, então ministro da fazenda usará em sua campanha presidencial, bem como alguns ensaios no que se refere ao enxugamento do Estado. No entanto, é no governo FHC - eleito em 1994 - que o projeto neoliberal se consolida e avança (NEVES, 1996: p. 82-83), alinhando-se de forma ainda mais subordinada ao Capital Internacional, cujas políticas de ajuste sócio-econômico ao paradigma da Acumulação Flexível (NEVES, 1996: p. 77) são propagandeadas por instituições financeiras internacionais como o FMI e sobretudo o Banco Mundial. Este último, segundo Maria Clara Couto Soares: 
[...] exerce profunda influência nos rumos do desenvolvimento mundial. Sua importância hoje devese não apenas ao volume de seus empréstimos e a abrangência de suas áreas de atuação, mas também ao caráter estratégico que vem desempenhando no processo de reestruturação neoliberal dos países em desenvolvimento por meio de políticas de ajuste estrutural (SOARES in DE TOMASI, 1996: p. 15).

Nesse contexto, sob a égide da globalização, que se reveste de nuances diferenciadas de acordo com a forma de inserção dos países nesta fase do capitalismo, acentua-se o paradigma da competitividade: "a competitividade das empresas é a condição número um da sobrevivência" (LESBAUPIN \& ABREU, 1996: p. 10).

Para competir numa economia globalizada, as empresas nacionais - ou multinacionais no Brasil - aceleram as redefinições no processo produtivo investindo em tecnologia, automatização de base microeletrônica, implementando políticas de qualidade total, passando-se a exigir cada vez mais do trabalhador conhecimentos técnicos, numa perspectiva de visão do operário como elemento polivalente no setor da produção dentro da concepção de "especialização flexível" que teoricamente contrapõe-se a rigidez da mão-de-obra do modelo fordista. De acordo com Salm e Fogaça, referindo-se a um estudo feito pelo Instituto de Economia Industrial da UFRJ: "A pesquisa detectou uma notável convergência quanto à importância atribuída a qualificação dos recursos humanos" (SALM \& FOGAÇA, 1992: p. 114).

Com a consolidação do projeto neoliberal no contexto brasileiro em 1994, o empresariado, elegendo a educação como imprescindível ao aumento da produtividade e da competitividade, passam a reivindicar seus interesses nessa área social, como a universalização do $1^{\circ}$ grau e ensino médio. Tal ensejo do empresariado é contemplado quando o MEC passa a ser dirigido pelo economista Paulo Renato de Souza, que começa a implementar de fato no ensino, o "padrão neoliberal de qualidade" 
(SALM \& FOGAÇA, 1992: p. 94). Assiste-se, a partir desse momento, a submissão do MEC ao Ministério do Trabalho, que passa a atuar de acordo com as deliberações do Programa Brasileiro de Qualidade e Produtividade - PBQP - e do Programa de Apoio Científico e Tecnológico - PACT (NEVES, 1997: p. 79).

O MEC passa a ser um apêndice onde as exigências do Capital consolidadas junto ao Ministério do Trabalho, redefinem as políticas educacionais através da nova LDB e promovem modificações substanciais, considerando-se a lei que vigora e o projeto que estava em tramitação no congresso, e que foi substituído.

No que se refere aos financiamentos e investimentos do Banco Mundial para o Brasil, estes se orientam de acordo com os pressupostos de Theodore Schultz. Ao relacionar investimentos e desenvolvimento econômico nos países em desenvolvimento, o autor afirma que:

O novo capital destinado a esses países, vindo de fora, como regra vai para a formação de estruturas, de equipamentos e algumas vezes para bens e mercadorias inventariadas. Mas em geral não é disponivel para um investimento adicional no homem. conseqüentemente, as capacitações humanas não se colocam ombro a ombro com o capital físico, e se transformam na verdade em fatores limitativos ao crescimento econômico (SCHULTZ, 1973: p. 40-41).

Essa argumentação de Schultz em 1971 - no momento da crise do taylorismo-fordismo se faz presente nas análises do Banco Mundial em 1995 (DE TOMMASI, 1996: p. 195-196). Fica clara a influência teórica de Schultz na construção de um economicismo em educação, como também na ampliação do conceito de capital. Neste conceito, o investimento em saúde, lazer, imigração e aquisição de conhecimentos técnicos e qualificação, potencializa os ganhos das empresas e do trabalhador em relação ao capital físico, e contribuem para a 
formação, segundo Schultz, de um capital produtivo que seria de posse do trabalhador. Esse investimento em seres humanos, formaria o capital humano que acrescentaria ganhos produtivos quando somados ao capital físico e explicaria o crescimento econômico nos países de capitalismo avançado (SCHULTZ, 1973: p. 42-43).

Nesta visão teórica a despeito da argumentação de Schultz (1973: p. 61) acentua-se uma tendência a desumanização do trabalhador na medida em que sua valorização social se dá em relação ao seu nível de capacitação e contribuição para a produção ("o valor de uma pessoa em relação a outras é medido por qualquer excesso de sua contribuição para a produção sobre o que consome da produção..."), como também se justifica as desigualdades de renda, relacionando-a com maior qualificação ou menor qualificação, deslocando o problema para fora das relações de poder e de classe.

No desenrolar do processo político brasileiro, o governo FHC amplia o conceito de Educação Básica que de 8 passa a ter 11 anos, mais a educação pré-escolar, incluindo nessa concepção - $2^{\circ}$ grau ou nível médio, aumentando o nível de escolaridade, o que segundo Salm e Fogaça são extremamente importantes para o próprio uso ou consumo dos produtos gerados pelas novas tecnologias (bens ou serviços), pois, segundo os autores, tal consumo e o nível de compreensão do funcionamento de tais produtos está diretamente ligado a uma base de educação geral, bem acima da média da população brasileira (SALM \& FOGAÇA, 1992: p. 125).

As concepções da Teoria do Capital Humano que norteiam o modelo educacional neoconservador, procuram negar as desigualdades sociais como fruto de uma estrutura de classe e da lógica excludente do capitalismo. Tal visão tenta propagandear essa problemática como resultado da falta de conhecimentos técnicos e qualificação profissional, que seriam sanados mediante o investimento em educação, e, segundo afirmação de KANITZ para a imprensa, uma vez alcançadas essa metas de investimento, conforme tenta se ideologizar junto ao senso comum, a divisão não se daria mais entre ricos e pobres mas 
sim entre competentes e incompetentes (VEJA, 04/03/1998: $p$. 46). Vejamos o que diz Frigotto acerca dessa concepção:

Por ser uma formulação que olha a relação capitalista de dentro e o sistema como um dado resultante da perspectiva liberal neoclássica de compreensão da realidade social, não leva em conta as relações de poder, as relações de força, os interesses antagônicos e conflituosos e portanto as relações de classe. A debilidade da tese do capital humano de gerar política e socialmente o que prometia em termos das nações e dos indivíduos resulta, pois, da forma invertida de apreender a materialidade histórica das relações econômicas, que são relações de poder e de força e não uma equação matemática como querem os neoclássicos ou neoconservadores (FRIGOTTO, 1995: p. 93).

Ou seja, o projeto neoconservador tenta legitimar tais relações obscurecendo a lógica real de exclusão social que, historicamente vem sendo a tônica do capitalismo. Nesse aspecto o acentuamento da exploração e da desumanização do trabalhador se faz concreta não só pelas redefinições dos conceitos no campo da produção e da educação onde ele se insere, mas também pelo fato de que suas conquistas sociais se encontram solapadas. Assiste-se ao desmonte do Estado nacional e a substituição das políticas social-democratas como potenciais "equalizadoras" das desigualdades; o Estado diminui sensivelmente sua atuação social, sendo substituído nessa função pela iniciativa privada. Nessa visão, questões de ordem política e social no campo educacional são transformadas em questões técnicas, e a problemática enfrentada pela educação é deslocada para uma relação de "eficácia/ineficácia" na gerência e administração de recursos humanos e materiais" (SILVA \& GENTILI, 1995: p. 22).

Em relação a distância entre prática política e discurso, tal distanciamento é evidente. Ao passo que a elite dominante vem 
propagandeando a ampliação das oportunidades educacionais, chegando até a materializar tal discurso em ações concretas de ampliação do sistema escolar ou em reformulações na regulação da educação nacional, evidencia-se a preocupação primordial em aumentar a produtividade do trabalho na sociedade urbanoindustrial, de modo a garantir a inserção do Brasil na globalização da economia, objetivando, através da potencialização do trabalho humano recompor as bases de acumulação abaladas, privilegiando apenas um nível educacional - o nível básico - em detrimento de outro que prepare o indivíduo com patamares de conhecimentos superiores. Isso gera ambigüidades na política educacional, pois esta, na medida em que é implementada, cria obstáculos ao acesso das classes populares ao nível superior de ensino. Nesse momento histórico, o Governo Brasileiro tem demonstrado preocupação apenas em assegurar o ensino fundamental, esquivando-se da sua condição de promotor e assegurador da educação em outros níveis. Esse fato pode ser observado na síntese de uma entrevista concedida pelo Ministro de Educação Paulo Renato de Souza à Revista Exame, citada por Frigoto no prefácio do livro "Brasil Ano 2000: Uma Nova Divisão de Trabalho em Educação":

Segundo o Ministro, a ênfase no ensino Universitário foi uma característica de um modelo de desenvolvimento auto-sustentado, desplugado da economia internacional e hoje em estado de agonia terminal. Para mantê-lo era necessário criar uma Pesquisa e Tecnologia próprias, diz Paulo Renato. Com a abertura e globalização, a coisa muda de figura. $O$ acesso ao conhecimento fica facilitado, as associações Joint Ventures se encarregam de prover as empresas dos países como o Brasil do Know-How que necessitam. 'Alguns países como a Coréia, chegaram a terceirizar a Universidade', diz Paulo Renato. 'Seus melhores quadros vão estudar em escolas dos Estados Unidos e da Europa. Faz mais sentido do ponto de vista econômico' (NEVES, 1997: p. 12). 
Não precisa afirmar que parte esse "ponto de vista econômico" revela-se extremamente excludente, passando também pela subordinação científica e teconlógica cada mais acentuada do Brasil aos países capitalistas centrais.

Portanto, as redefinições na política educacional do Brasil nos anos 90 delimitam funções sociais e se orientam, mais uma vez, no sentido de tentar reverter uma queda tendencial nas taxas de lucro do setor produtivo através do agudização da extração de mais-valia relativa, se revelando uma estratégia para a recomposição de capital. Ou seja, às classes populares assegurase apenas a Educação Básica garantida pelo Estado, educação essa provida com métodos de qualidade duvidosas, como a educação à distância e com currículos do $2^{\circ}$ grau que privilegiam apenas os aspectos técnicos, objetivando apenas fornecer mãode-obra à demanda do setor produtivo - e formar também um exército trabalhador reserva - como também constituir uma massa de consumidores para os modernos produtos deste fim de século.

Acentua-se, dessa maneira, a posição da classe trabalhadora de menor renda na constituição de uma massa humana destinada ao trabalho simples. Por outro lado, o acesso ao $3^{\circ} \mathrm{grau}$, na medida em que é impossibilitado para as classes populares, fica reservada às camadas da população que podem ter como alternativa o ensino pago, um modelo educacional que, teoricamente, pode vir a preparar o indivíduo com outros conteúdos que não sejam apenas técnicos, numa concepção educacional mais avançada, estabelecendo uma relação mais próxima entre a educação básica e a universidade; relega-se, então, a essa classe o papel de realizar o trabalho complexo.

Evidencia-se, portanto, na conjuntura atual dois modelos educacionais para a classe trabalhadora: o primeiro refere-se a educação baseada na concepção de polivalência, que se norteia pela formação de um profissional multi-função, o que, segundo Machado (MACHADO, 1992: p. 19-22) , pressupõe apenas um trabalho mais variado numa visão utilitarista, sem importar necessariamente numa mudança qualitativa das tarefas e, sobretudo, vale destacar, com um nível de qualificação que na 
verdade aponta para uma desqualificação relativa - quando não absoluta em decorrência da perda do ofício para a moderna maquinaria - em relação aos reais avanços da ciência; a outra, infelizmente mais discutida no meio acadêmico, seria a politecnia ou Escola Unitária - numa concepção gramsciana -, representada, segundo Machado (a autora se refere à politecnia), pelo domínio da técnica a nível científico possibilitando um "trabalho flexível com recomposição das tarefas a nível criativo" (MACHADO, 1992: p. 19), revelando-se numa concepção educacional extremamente avançada.

Diante do quadro aqui exposto, observa-se, a curto e médio prazos, uma tendência à generalização da primeira concepção polivalência -, quanto à segunda - politecnia ou Escola Unitária - somente a correlação de forças entre Capital/Trabalho definirá o seu encaminhamento no seio da sociedade contemporânea.

\title{
Agradecimentos
}

Gostaria de agradecer ao prof. José dos Santos Souza pelas observações oportunas sobre o trabalho, apontando, quando necessário, alguns pontos a serem melhorados na abordagem que nos propusemos a realizar neste artigo. Gostaria de agradecer também a contribuição dos autores cujas as obras citadas na bibliografia me serviram de referência, pois, direta ou indiretamente, o conhecimento é, antes de tudo, uma construção coletiva.

\begin{abstract}
In the decade of 1930 the capitalism was itself in crisis. Such crisis is resolved through structual reforms and, in the years of 1950-60 the sistem equilibrates. Yet, in the beginning of the decade of 1970 a new crisis start, and this perpetuates nowadays. According to this process, one of the appointed estrategies by the bourgesise to return the process of crisis, is the subordinated enlargement of the schooling of the workman.
\end{abstract}

Key-words: 1. Fordism 2. Capitalist crisis 3. Neoliberalism 4. Brasilian Education. 


\section{Referências Bibliográficas}

BRASIL. Lei n 9394, de 20/12/1996, Ministério da Educação e do Desporto.

DE TOMMASI, Livia. Financiamentos do banco Mundial no Setor Educacional brasileiro: os projetos em fase de implementação. In: DE TOMMASI, Livia, WARDE, Mirian J. HADDAD, Sergio (orgs). O Banco Mundial e as Políticas Educacionais. São Paulo: Cortez, 1996.

FRIGOTTO, Gaudêncio. Os Delírios da Razão: Crise do Capital e Metamorfose Conceitual no Campo Educacional. In: GENTILI, Pablo (org.). Pedagogia da Exclusão: Crítica ao Neoliberalismo em Educação. Petrópoles: Vozes, 1995. HOBSBAWM, Eric J. Era dos Extremos: O breve século XX: 1914 - 1991. São Paulo: Companhia da Letras, 1995.

KANITZ, Stephen. "O Fim da Incompetência". Revista Veja, 04/03/1998, p. 46.

LARANJEIRA M. G., Sônia. Fordismo e pós-Fordismo. In: CATANI. D., Antônio (org.). Trabalho e Tecnologia: Dicionário Crítico. Petrópolis: Vozes; Porto Alegre: Ed. Universidade, 1994.

LESBAUPIN, Ivo; ABREU, Antônio. "Conjuntura Sócioeconômico-Política Brasileira". In: Cadernos do CEAS, Salvador $n \cong 170,1997$.

NEVES, Lúcia M. W. Brasil Ano 2000: Uma nova Divisão de Trabalho na Educação. Rio de Janeiro: Papéis e Cópias, 1996.

SALM, Cláudio; FOGAÇA, Azuete. "Modernização Industrial e a Questão dos Recursos Humanos". In: Economia \& Sociedade, Campinas $\mathrm{n} \cong 1$, p. 111-114, Março/Agosto 1992.

SCHULTZ, Theodore W. . O capital Humano: Investimentos em Educação e Pesquisa. Rio de Janeiro: Zahar Editores, 1973.

SILVA, Tomaz Tadeu da. A "Nova" Direita e as Transformações na Pedagogia da Política e na Política da Pedagogia. In: GENTILI, Pablo, SILVA, Tomaz Tadeu da. (orgs). 
Neoliberalismo, Qualidade Total e Educação. 2a. Edição. Rio de Janeiro. Petrópoles: Vozes, 1995.

SOARES, Maria Clara Couto. O Banco Mundial, Políticas e Reformas. In: De TOMASI, WARD e HADDAD (orgs.). $O$ Banco Mundial e as políticas educacionais. São Paulo: Cortez, 1996.

SOUZA, José dos Santos. Crise do Capital e Redefinição da Política Educacional Brasileira nos anos 90. Vitória da Conquista: 1998, mimeo.

MACHADO, Lucília Regina de S. Mudanças Tecnológicas e a Educação da Classe Trabalhadora. In: Coletânea CBE: Trabalho e Educação. Campinas - SP: Papirus, 1992. P. 9-23. 